\title{
Extração e fracionamento de óleo e compostos fenólicos de resíduos de café utilizando tecnologia supercrítica.
}

\section{Fernando M. P. A. Mello*, Raphaela G. Bittencourt, Fernando A. Cabral. \\ Resumo}

Este projeto estudou a extração e fracionamento do óleo de resíduos de café utilizando tecnologia supercrítica e diferentes métodos/solventes para extração. Todas as frações obtidas dos fracionamentos via precipitação foram analisadas quanto a rendimentos de extração e teor de compostos fenólicos totais.

\section{Palavras-chave:}

Fracionamento, óleo de café, dióxido de carbono supercrítico.

\section{Introdução}

A indústria de café é responsável pela geração de resíduos orgânicos, como a borra e torta de café, os quais contêm óleo vegetal e compostos fenólicos em sua composição. A utilização da tecnologia supercrítica para obtenção de extratos tem sido explorada por obter bons rendimentos de extração com alto grau de pureza. Um fluido supercrítico é definido como uma substância que se encontra acima de sua temperatura e pressão críticas (Tc e Pc), favorecendo a capacidade de solvatação e a penetração do fluido na matriz vegetal. Além disso, tendo em vista que $\mathrm{O}^{\mathrm{CO}_{2}}$ é inerte e não tóxico, seu uso apresenta-se como destaque para produzir extratos naturais contendo substâncias bioativas. $O$ uso de etanol como cossolvente modifica a solubilidade dos compostos extraídos em fluidos supercríticos. Neste contexto, este projeto objetiva estudar a extração e fracionamento do óleo de café utilizando tecnologia supercrítica.

\section{Resultados e Discussão}

Diferentes métodos de extração foram testados para a borra de café: método Soxhlet utilizando etanol e hexano como solvente, e extração em leito fixo à alta pressão com diferentes tipos de solventes $\left(\mathrm{scCO}_{2}\right.$, etanol e mistura $\mathrm{scCO}_{2}+$ etanol). Também foi realizada uma extração sequencial com $\mathrm{scCO}_{2}$, seguida de etanol. A Tabela 1 apresenta os rendimentos globais de extração para cada método. Quando é utilizado etanol como cossolvente, a extração com $\mathrm{scCO}_{2}$ tem maior rendimento, o que pode ser atribuído as modificações físico químicas do sistema, aumentando a solubilidade lipídica.

A análise de concentração em compostos fenólicos (TCF) apresentou os maiores valores para os extratos etanólicos, e o TCF do extrato obtido com $\mathrm{scCO}_{2}$ é maior do que o obtido via soxhlet com hexano. Além disso, a segunda etapa da extração sequencial forneceu um extrato com concentração de fenólicos 4 vezes maior que o extrato etanólico em etapa única.

Experimentos de fracionamento foram realizados para verificar a precipitação dos compostos presentes nas amostras. Foram utilizados 4 separadores, que operavam em diferentes condições de pressão. A Figura 1 apresenta os valores de rendimento e TCF em cada separador. As maiores precipitações foram observadas nos separadores 3 e 4, nos quais as pressões eram 100 bar e $P_{\text {atm }}$, respectivamente. Porém, o maior TCF foi observado no separador 1.

Tabela 1. Rendimentos (Y) de extratos da borra de café por diferentes extrações e solventes.

\begin{tabular}{ccc}
\hline Método & $\mathbf{P} / \mathbf{T}$ & $\mathbf{Y}(\%)$ \\
\hline Soxhlet Etanol & Patm $/$ Tebu & $26,01 \pm 0,48$ \\
\hline Soxhlet Hexano & Patm $/$ Tebu & $20,01 \pm 0,50$ \\
\hline $\mathrm{scCO}_{2}$ & $400 \mathrm{bar} / 60^{\circ} \mathrm{C}$ & $20,03 \pm 0,86$ \\
\hline Etanol & $400 \mathrm{bar} / 60^{\circ} \mathrm{C}$ & $25,09 \pm 0,43$ \\
\hline $\begin{array}{c}\mathrm{scCO}_{2}+\mathrm{Etanol} \\
(90: 10 \mathrm{~m} / \mathrm{m})\end{array}$ & $400 \mathrm{bar} / 60^{\circ} \mathrm{C}$ & $23,02 \pm 0,79$
\end{tabular}

Sequencial

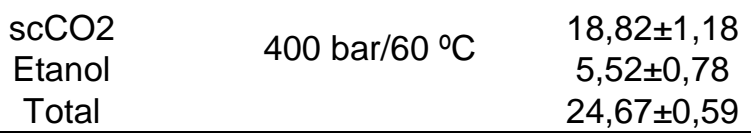

Patm: Pressão atmosférica de Campinas/SP.

Tebu: Temperatura de ebulição do solvente

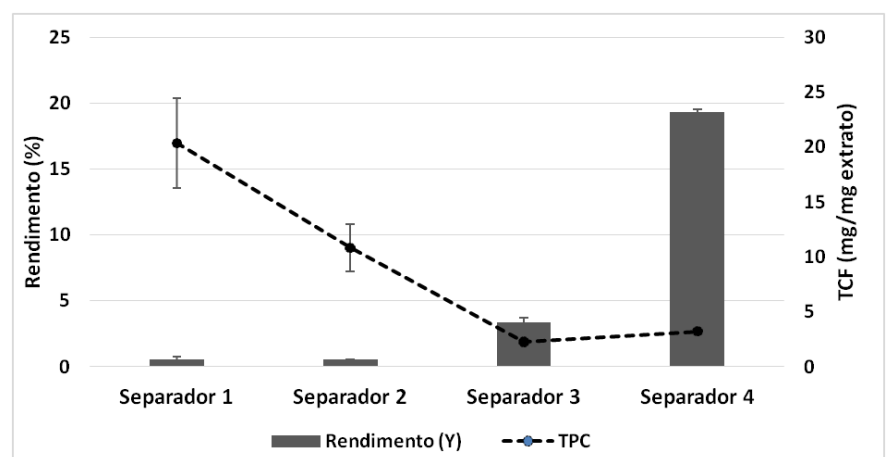

Figura 1. Rendimento e teor de fenólicos obtidos pelo fracionamento do extrato etanólico da borra de café

\section{Conclusões}

O reaproveitamento dos resíduos industriais de café importância visto que estes ainda tem potencial de aplicação, com rendimentos de extração superiores a $20 \%$ e extratos enriquecidos em compostos fenólicos pelos fracionamentos via precipitação.

\section{Agradecimentos}

À Faculdade de Engenharia de Alimentos da UNICAMP., aos docentes e a FAPESP (Projeto número 09931-5) pelo suporte fornecido neste projeto. 